\title{
Cryobiopsy In Flexi-Rigid Pleuroscopy in a Region with Low Mesothelioma Prevalence
}

\author{
Authors: \\ *Larry Ellee Anak Nyanti, ${ }^{1}$ Sze Shyang Kho, ${ }^{1}$ Chan Sin Chai,, Fatin Izni \\ Nazri, ${ }^{2}$ Siew Teck Tie ${ }^{1}$ \\ 1. Division of Respiratory Medicine, Sarawak General Hospital, Kuching, Malaysia \\ 2. Department of Pathology, Sarawak General Hospital, Kuching, Malaysia \\ *Correspondence to larryen90@yahoo.com \\ Disclosure: $\quad$ The authors have declared no conflicts of interest. \\ Received: $\quad 02.03 .20$ \\ Accepted: $\quad 09.06 .20$ \\ Keywords: $\quad$ Flexi-rigid cryobiopsy, lactate dehydrogenase (LDH), local anaesthetic thoracoscopy, \\ medical thoracoscopy, mesothelioma, pleuroscopic cryobiopsy, pleuroscopy, semi- \\ rigid cryobiopsy. \\ Citation: $\quad$ EMJ Respir. 2020;8[1]:137-145.
}

\begin{abstract}
Background: The use of conventional flexible forceps during flex-rigid pleuroscopy can be challenging when sampling hard and thickened pleura. Pleuroscopic cryobiopsy is an emerging field, with various early studies demonstrating good yield and minimal complications.
\end{abstract}

Objectives: To review the authors' early experience of pleuroscopic cryobiopsy in their centre and highlight its utility in the diagnosis of mesothelioma.

Method: Six cases of undiagnosed pleural effusion that underwent pleuroscopic cryobiopsy via flexi-rigid pleuroscopy between July 2017 and June 2019 were retrospectively analysed.

Results: The cohort had a median age of 59 years, consisting of two females and four males with a median age of 57 years. Mean (aggregate) tissue sample diameter was $9.2 \pm 1.9 \mathrm{~mm}$. Cryobiopsy established a definitive diagnosis in all six cases: one case of malignant mesothelioma, one pleural tuberculosis, two small cell carcinomas, and two adenocarcinomas. Immunohistochemical staining was performed in all five of the malignant samples (100\%). There were no major complications reported.

Conclusions: Based on the case series, pleuroscopic cryobiopsy is a feasible adjunct to conventional forceps biopsy, a safe procedure in the authors' setting, gives high diagnostic yield, and enables differentiation between the different causes of exudative pleural effusion. A large, prospective study is required to validate this retrospective series.

\section{INTRODUCTION}

or video-assisted thoracic surgery (VATS). While VATS is considered the gold standard,

Following diagnostic thoracocentesis and closed pleuroscopy is a less invasive, simpler, and costpleural biopsy, $25 \%$ of pleural effusions remain effective alternative with a favourable diagnostic undiagnosed,' requiring either pleuroscopy yield. ${ }^{2}$ Furthermore, VATS is not always available, 
and is sometimes contraindicated, especially in patients with high surgical risk or advanced metastatic malignancy. ${ }^{2}$

Rigid pleuroscopy demonstrates higher yields of $97.8 \%$ versus $73.3 \%$ for flexi-rigid pleuroscopy due to larger sample sizes, superiority in sampling fibrous pleura in suspected mesothelioma, and its effectiveness in adhesiolysis. ${ }^{3}$ On the other hand, advantages for flexi-rigid pleuroscopy include less pain and easier maneuverability. ${ }^{4,5}$ Efforts to increase yield of flexi-rigid pleuroscopy has led to the use of cryobiopsy, a technique previously validated for endobronchial and transbronchial biopsies. ${ }^{6}$ Cryobiopsy through flexi-rigid pleuroscopy is an emerging technique which carries the promise of both larger sample size with preserved tissue architecture, while maintaining ease of manoeuvrability with a flexible pleuroscope.

In the Southeast Asia region, the incidence of mesothelioma is lower compared with European or Oceanian countries. Many benign pleural diseases mimic similar histopathological changes in mesothelioma; ${ }^{7}$ therefore, proper acquisition of tissue is important in Malaysia to ensure a diagnosis of mesothelioma is not missed.

\section{MATERIALS AND METHODS}

Six patients with malignancy-suspicious pleural effusion who underwent pleuroscopic cryobiopsy at the authors' unit between July 2017 and June 2019 were analysed. In that period, a total of 244 patients underwent pleuroscopic biopsy: 14 via rigid pleuroscope, 224 via flexi-rigid pleuroscope using conventional forceps, and six via flexi-rigid pleuroscope using cryobiopsy. Written informed consent was obtained from all patients. Pleural fluid analysis was performed via ultrasoundguided diagnostic thoracocentesis prior to the procedure. Baseline blood investigations including coagulation profile were taken for each patient and ensured normal prior commencing the procedure.

Transthoracic ultrasound was performed on each patient to identify the safe entry site with the patient in lateral position with the abnormal side upwards. The procedure was performed under conscious sedation with intravenous midazolam and pethidine. Under aseptic technique, the entry site was infiltrated with local anaesthesia (2\% lidocaine). Flexible electrocautery equipment were prepared for any potential bleeding complications.

A $1.5 \mathrm{~cm}$ incision was then made on the skin and blunt dissection was performed until the pleura was breached. A $11 \mathrm{~mm}$ metallic trocar was then inserted into the pleural cavity for pneumothorax induction. Pleuroscopy was performed using a flexi-rigid scope (LTF-160, Olympus, Tokyo, Japan) passed through the trocar. All pleural fluid was aspirated until clear to allow clear examination of the pleural cavity. Pleural fluid was sent for further analysis if initial diagnostic thoracocentesis data was inadequate.

After cautious examination of the pleural cavity, cryobiopsies were obtained at visibly abnormal areas using a $950 \mathrm{~mm}$ cryoprobe of either 1.9 or $2.4 \mathrm{~mm}$ diameter passed through the working channel of the pleuroscope in conjunction with the ERBECRYO ${ }^{\circledR} 2$ system (Erbe Medizintechnik, Tübingen, Germany). Carbon dioxide was used as cryogen. The tip of the cryoprobe was applied to the target biopsy sites and activated for a minimum time of $3 \mathrm{sec}$ under direct vision, and pleural specimens were removed by extracting the cryoprobe and flexi-rigid scope together through the trocar. The specimen was thawed in normal saline, placed into formalin solution, and immediately sent to the laboratory for histopathological analysis. Meanwhile, the pleuroscope was reinserted into the pleural cavity to assess for any bleeding or complication. The biopsy procedure was repeated for a minimum of three times, given that no complications occurred. The decision to employ cryobiopsy was at the discretion of the endoscopist when specimen from forceps biopsy was deemed inadequate during intraprocedure.

\section{CASE SERIES}

\section{Case 1}

Case 1 was a 64-year-old indigenous Malaysian female who did not smoke and had no underlying medical illness. She presented with 1 week of progressively worsening shortness of breath on a background of 1 month of persistent nonproductive cough and loss of appetite. When asked, she did not report any fever or night sweats. Clinically, she was not tachypnoeic but had finger clubbing and reduced air entry over 
the left lower zone of the chest. Her vitals were unremarkable with a temperature of $36.6{ }^{\circ} \mathrm{C}$ and oxygen saturation of $97 \%$ under room air. Chest radiograph showed blunting of the left costophrenic angle and ultrasound of the thorax confirmed a left non-loculated pleural effusion. Her total white cell count was $6.7 \times 10^{9}$ cells $/ \mathrm{L}$. Pleural fluid parameters were exudative $(\mathrm{pH}=$ 7.355; pleural fluid:serum protein ratio $=50 / 72$ $\mathrm{g} / \mathrm{L}$; pleural fluid:serum lactate dehydrogenase $[\mathrm{LDH}]$ ratio $=1554 / 426 \mathrm{U} / \mathrm{L}$; fluid glucose $=$ $4.8 \mathrm{mmol} / \mathrm{L}$ ); pleural fluid cytology showed no malignant cells. Pleuroscopy revealed multiple pleural and diaphragmatic nodules; cryobiopsy was performed with no major complication. Talc pleurodesis was applied prior to removal of the chest drain. Histopathological and immunohistochemical examination confirmed epidermal growth factor receptor-positive lung adenocarcinoma, and she was referred to the oncology team for commencement of tyrosinekinase inhibitor therapy.

\section{Case 2}

Case 2 was a 59-year-old Malay male with a 50-pack per year smoking history, underlying hypertension, and dyslipidaemia, who presented with 1 week of right lateral chest pain and shortness of breath on a background of chronic dry cough of 2 months, accompanied by loss of weight and appetite. He did not have a history of fever. On clinical examination, he was tachypnoeic with a respiratory rate of 24 breaths per minute and oxygen saturation of $92 \%$ under room air. He had no finger clubbing; chest examination demonstrated reduced air entry over the right lower and middle zones. His temperature was $36.5{ }^{\circ} \mathrm{C}$ and his total white cell count was $7.7 \times 10^{9}$ cells/L. Chest radiograph showed a right homogenous opacity with meniscus sign obliterating the right heart border. Ultrasound thorax confirmed a non-loculated right pleural effusion. Pleural fluid parameters were exudative $(\mathrm{pH}=7.531$; pleural fluid:serum protein ratio $=42 / 72 \mathrm{~g} / \mathrm{L}$; pleural fluid:serum $\mathrm{LDH}$ ratio $=$ $722 / 894 \mathrm{U} / \mathrm{L}$; pleural fluid glucose $=5.3 \mathrm{mmol} / \mathrm{L}$ ); pleural fluid cytology showed no malignant cells. Pleuroscopy showed multiple visceral and parietal pleural nodules; cryobiopsy was performed with no major complication. Talc pleurodesis was applied prior to removal of the chest drain. Histopathological and immunohistochemical examination confirmed small cell carcinoma of the lung, and he was referred to the oncology team for further management.

\section{Case 3}

Case 3 was a 60-year-old indigenous Malaysian female who did not smoke and had a history of right breast carcinoma in 1999, for which she had a right mastectomy and subsequently had been in stable remission. In December 2017, she presented with 2 weeks of shortness of breath and right lateral chest discomfort for 3 days, but, when asked, did not report any fever, cough, night sweats, or overt loss of weight. On clinical examination, she had a respiratory rate of 23 breaths per minute, temperature of $36.2^{\circ} \mathrm{C}$, and oxygen saturation of $90 \%$ under room air, with chest examination demonstrating reduced air entry over the entire right thorax. Her total white cell count was $8.3 \times 10^{9}$ cells/L. Chest radiograph revealed a 'white-out' appearance of the right lung. Ultrasound thorax confirmed a very large non-loculated right pleural effusion. Pleural fluid parameters were protein-discordant exudative $(\mathrm{pH}=7.497$; pleural fluid:serum protein ratio $=34 / 74 \mathrm{~g} / \mathrm{L}$; pleural fluid:serum LDH ratio $=472 / 400 \mathrm{U} / \mathrm{L} ;$ pleural fluid glucose $=3.6$ $\mathrm{mmol} / \mathrm{L}$ ); pleural fluid cytology was inconclusive, showing malignant cells. Pleuroscopy showed multiple diaphragmatic nodules; cryobiopsy was performed with no major complication. Talc pleurodesis was administered prior to chest tube removal. Histopathological and immunohistochemical examination confirmed metastatic adenocarcinoma secondary to her primary breast malignancy. She underwent palliative treatment under the oncology team. As of 18 months after the cryobiopsy, surveillance CT did not show further progression of disease.

\section{Case 4}

Case 4 was a 67-year-old Malay male who did not smoke but did have underlying Type 2 diabetes mellitus and was on insulin treatment. He presented in January 2019 with complaints of fever, shortness of breath, and loss of appetite for 2 weeks, associated with right lateral chest discomfort. He did not report any chronic cough or haemoptysis. On clinical examination, he had a respiratory rate of 22 breaths per minute, temperature of $37.1^{\circ} \mathrm{C}$, and oxygen saturation of $95 \%$ under room air, with chest examination 
showing reduced air entry over the right lower zone. His total white cell was $6.8 \times 10^{9}$ cells/L. Chest radiograph showed a right homogenous opacity with meniscus sign partially obliterating the right heart border. Ultrasound thorax revealed a non-loculated pleural effusion. Pleural fluid parameters were exudative $(\mathrm{pH}=7.466$; pleural fluid:serum protein ratio $=59 / 78 \mathrm{~g} / \mathrm{L}$; pleural fluid:serum LDH ratio $=330 / 612 \mathrm{U} / \mathrm{L}$; pleural fluid glucose $=10.38 \mathrm{mmol} / \mathrm{L})$; pleural fluid cytology showed predominantly lymphocytic effusion. Sputum examination for acid-fast bacilli was negative. Pleural fluid and sputum culture for tuberculosis were negative. Pleuroscopy revealed multiple parietal pleural nodules, several of which were tangentially oriented; cryobiopsy was performed with no major complication. No talc pleurodesis was given in view of suspected tuberculous infection. Histopathological and immunohistochemical examination confirmed caseating granulomas; the patient was started on tuberculosis treatment, after which clinical improvement in terms of weight gain, symptom resolution, and radiological improvement as evidenced by eventual resolution of the effusion on chest radiographs were demonstrated.

\section{Case 5}

Case 5 was a 58-year-old Malay male who smoked but had no underlying medical illness. He presented in June 2019 with a 3-month history of chronic cough and loss of weight and appetite. He did not report fever and haemoptysis. Clinically, he had a respiratory rate of 24 breaths per minute, temperature of $37.0^{\circ} \mathrm{C}$, and oxygen saturation of 93\% under room air. He was clinically clubbed, and chest examination revealed reduced air entry over the left lower and mid zone. Chest radiograph showed a left homogenous opacity with meniscus sign and obliteration of the left heart border. Ultrasound of the thorax showed a non-loculated left pleural effusion. His total white cell count was $9.9 \times 10^{9}$ cells/L. Pleural fluid parameters were exudative $(\mathrm{pH}=7.394$; pleural fluid:serum protein ratio $=45 / 77 \mathrm{~g} / \mathrm{L}$; pleural fluid $\mathrm{LDH}=207 \mathrm{U} / \mathrm{L}$; pleural fluid glucose = $6.8 \mathrm{mmol} / \mathrm{L}$ ); pleural fluid cytology showed no malignant cells. Pleuroscopy revealed multiple pleural and diaphragmatic nodules; cryobiopsy was performed with no major complication. Talc pleurodesis was applied prior to removal of the chest drain. Histopathological and immunohistochemical examination confirmed small cell carcinoma of the lung. He was referred to the oncology team for further care.

\section{Case 6}

Case 6 was a 71-year-old indigenous Malaysian male who smoked and had a history of asbestos exposure. He presented in June 2019 with a 2-month history of progressive shortness of breath and dry cough, associated with loss of weight. He did not report fever or haemoptysis. Clinically, he had a respiratory rate of 23 breaths per minute, temperature of $36.8^{\circ} \mathrm{C}$, and oxygen saturation of $91 \%$ under room air. Chest examination revealed reduced air entry over the right lower and midzone. Chest radiograph revealed a right homogenous opacity with meniscus sign and obliteration of the right heart border. Ultrasound of the thorax showed a non-loculated right pleural effusion. His total white cell count was $7.9 \times 10^{9}$ cells/L. Pleural fluid parameters were exudative $(\mathrm{pH}=7.258$; pleural fluid:serum protein ratio $=42 / 73 \mathrm{~g} / \mathrm{L}$; pleural fluid:serum $\mathrm{LDH}$ ratio $=954 / 321 \mathrm{U} / \mathrm{L}$; pleural fluid glucose $=5.1 \mathrm{mmol} / \mathrm{L}$ ); pleural fluid cytology was inconclusive, showing atypical cells. Pleuroscopy showed scattered small hard nodules; cryobiopsy was performed with no major complication. Talc pleurodesis was applied prior to removal of the chest drain. Histopathological and immunohistochemical examination confirmed malignant mesothelioma, and the patient was referred to the oncology team for further management.

\section{RESULTS}

\section{Baseline Demographic Data}

A total of six patients of either indigenous Malaysian or Malay descent underwent pleuroscopic cryobiopsy (Table 1). Two were female and four were male, with a median age of 59 years (interquartile range: 56-67).

\section{Characteristic of Pleural Effusion}

Two (33.3\%) of the effusions were left-sided, while four (66.7\%) were right-sided. All effusions had a simple appearance on ultrasound. 


\begin{tabular}{|c|c|c|c|c|c|c|}
\hline & \multicolumn{6}{|c|}{ Patient } \\
\hline & 1 & 2 & 3 & 4 & 5 & 6 \\
\hline Age (years) & 61 & 56 & 57 & 67 & 56 & 69 \\
\hline Gender & Female & Male & Female & Male & Male & Male \\
\hline $\begin{array}{l}\text { Effusion } \\
\text { laterality }\end{array}$ & Left & Right & Right & Right & Left & Right \\
\hline $\begin{array}{l}\text { Ultrasound } \\
\text { appearance }\end{array}$ & Simple & Simple & Simple & Simple & Simple & Simple \\
\hline $\begin{array}{c}\text { Pleural fluid } \\
\text { protein }(\mathrm{g} / \mathrm{dL})\end{array}$ & 50 & 42 & 34 & 59 & 45 & 42 \\
\hline Serum protein & 72 & 72 & 74 & 78 & 77 & 73 \\
\hline $\begin{array}{c}\text { Pleural fluid } \\
\text { LDH }\end{array}$ & 1554 & 722 & 472 & 330 & 207 & 954 \\
\hline Serum LDH & 426 & 894 & 472 & 612 & N/A & 321 \\
\hline $\begin{array}{c}\text { Pleural fluid } \\
\mathrm{pH}\end{array}$ & 7.355 & 7.531 & 7.497 & 7.466 & 7.394 & 7.258 \\
\hline $\begin{array}{l}\text { Pleural fluid } \\
\text { glucose }\end{array}$ & 4.8 & 5.3 & 3.6 & 10.38 & 6.8 & 5.09 \\
\hline $\begin{array}{c}\text { Pleural fluid } \\
\text { cytology }\end{array}$ & Not available & $\begin{array}{c}\text { No malignant } \\
\text { cells }\end{array}$ & Malignant cells & $\begin{array}{c}\text { Lymphocytic } \\
\text { effusion }\end{array}$ & $\begin{array}{l}\text { No malignant } \\
\text { cells }\end{array}$ & Atypical cells \\
\hline $\begin{array}{l}\text { Procedure } \\
\text { time (min) }\end{array}$ & 35 & 20 & 20 & 30 & 20 & 35 \\
\hline Appearance & Nodules & Nodules & Nodules & Nodules & Nodules & Nodules \\
\hline $\begin{array}{l}\text { Probe size } \\
(\mathrm{mm})\end{array}$ & 2.4 & 1.9 & 2.4 & 1.9 & 2.4 & 1.9 \\
\hline Complication & None & None & None & None & None & None \\
\hline HPE & $\begin{array}{c}\text { Lung } \\
\text { adenocarcinoma }\end{array}$ & $\begin{array}{l}\text { Small cell } \\
\text { carcinoma }\end{array}$ & $\begin{array}{c}\text { Lung } \\
\text { adenocarcinoma }\end{array}$ & $\begin{array}{c}\text { Caseating } \\
\text { granuloma, } \\
\text { negative ZN } \\
\text { stain }\end{array}$ & $\begin{array}{l}\text { Small cell } \\
\text { carcinoma }\end{array}$ & Mesothelioma \\
\hline IHC feasible? & Yes & Yes & Yes & No & Yes & Yes \\
\hline
\end{tabular}

HPE: histopathological examination; IHC: immunohistochemistry; LDH: lactate dehydrogenase; ZN: Ziehl-Neelsen.

Three (50.0\%) patients had effusions occupying one-half of the hemithorax, two patients (33.3\%) had effusions occupying less than one-half of the hemithorax, and one (16.7\%) had a massive white-out effusion. Pleural fluid $\mathrm{pH}$ was elevated in Cases 2, 3, and 4. Five of the effusions were exudative, one was protein-discordant (Case 3). Median pleural fluid protein was $43.5 \mathrm{~g} / \mathrm{dL}$ while median LDH was $597 \mathrm{IU} / \mathrm{L}$. Pleural fluid cultures were negative in all samples. Cytology was inconclusive in all six specimens, with only one sample showing malignant cells (Case 3 ) and another showing atypical cells (Case 6).

\section{Pleuroscopic Characteristic}

All six cases (100\%) had a nodular pleuroscopic appearance. A $1.9 \mathrm{~mm}$ probe was used in three cases $(50 \%)$, while a $2.4 \mathrm{~mm}$ probe was used in the other three cases (50\%). 
Table 2: Comparison to previous studies of pleuroscopic cryobiopsy.

\begin{tabular}{|c|c|c|c|c|c|c|c|}
\hline Studies & $\begin{array}{l}\text { Rozman et } \\
\text { al., } 2013\end{array}$ & $\begin{array}{c}\text { Thomas et al., }{ }^{9} \\
2015\end{array}$ & $\begin{array}{l}\text { Maturu et } \\
\text { al.,. }^{10} 2015\end{array}$ & $\begin{array}{l}\text { Chen et } \\
\text { al., }{ }^{4} 2018\end{array}$ & $\begin{array}{l}\text { Tousheed et } \\
\text { al.,"1 } 2018\end{array}$ & $\begin{array}{l}\text { Dhooria et } \\
\text { al.., }^{12} 2019\end{array}$ & $\begin{array}{l}\text { Present } \\
\text { series }\end{array}$ \\
\hline $\begin{array}{l}\text { Number of } \\
\text { subjects }\end{array}$ & 15 & 22 & 6 & 92 & 87 & 50 & 6 \\
\hline \multicolumn{8}{|c|}{ Quality of sample } \\
\hline Probe size & $2.4 \mathrm{~mm}$ & $2.4 \mathrm{~mm}$ & $1.9 \mathrm{~mm}$ & $1.9 \mathrm{~mm}$ & $2.4 \mathrm{~mm}$ & $2.4 \mathrm{~mm}$ & $1.9 / 2.4 \mathrm{~mm}$ \\
\hline Size $(\mathrm{mm})$ & $\mathrm{N} / \mathrm{A}$ & $\begin{array}{l}\text { Median: } 10 \\
\text { IQR: } 7.0-15.8\end{array}$ & $\begin{array}{l}\text { Mean: } \\
9.2 \pm 1.84\end{array}$ & $\begin{array}{l}\text { Mean: } \\
9.4 \pm 4.9\end{array}$ & $\begin{array}{l}\text { Mean: } \\
13.2 \pm 6.7\end{array}$ & $\begin{array}{l}\text { Median: } \\
\quad 7.0\end{array}$ & $\begin{array}{l}\text { Mean: } \\
9.2 \pm 1.9\end{array}$ \\
\hline $\begin{array}{l}\text { Diagnostic } \\
\text { yield (\%) }\end{array}$ & 15/15 (100) & $20 / 22(91)$ & $6 / 6(100)$ & $91 / 92$ (99) & 86/87 (99) & $39 / 50(78)$ & $6 / 6(100)$ \\
\hline $\begin{array}{l}\text { IHC stain } \\
\text { done (\%) }\end{array}$ & 13/13 (100\%) & N/A & $\mathrm{N} / \mathrm{A}$ & 91/92 (99) & $29 / 29(100)$ & N/A & $5 / 5(100)$ \\
\hline
\end{tabular}

IHC: Immunohistochemistry; IQR: interquartile range; N/A: not available.

Median activation time and the number of exact activations were not recorded in the patients. The mean aggregate sample size was $9.2 \pm 1.9$ $\mathrm{mm}$ (Table 2).4,8-12 A definite histopathological diagnosis was obtained in all six cases. Five (83.3\%) patients had confirmed malignancy (one adenocarcinoma lung, one adenocarcinoma breast, two small cell carcinomas, and one mesothelioma) and one (16.7\%) patient was diagnosed with pleural tuberculosis. The five (83.3\%) malignant samples were adequate for immunohistochemical staining. None of the six patients encountered major complications. The median procedural time was 25 minutes (range: 20-35 minutes).

\section{DISCUSSION}

Cryobiopsy is a technique that employs the use of a blunt probe cooled by nitrous oxide or carbon dioxide, which draws moisture out of surrounding tissue and freezes with it by creating a bond (Joule-Thomson effect). ${ }^{13}$ In pleuroscopic biopsy, cryobiopsy was historically performed with a rigid probe via a second trocar, under direct rigid pleuroscopy examination. ${ }^{13}$ Recent technological advancements have led to the flexible cryoprobe which can be inserted through the working channel of flexible endoscopes. The use of cryobiopsy in bronchoscopy has been validated in multiple studies for endobronchial biopsies and transbronchial biopsies with minimal additional bleeding risk. $^{6}$ Meanwhile, studies on cryobiopsy via flexi-rigid pleuroscopy have only recently burgeoned in the past decade, with studies citing comparable sample sizes and yield, preserved biopsy sample architecture allowing for immunohistochemical studies, and similar safety profile compared to conventional forceps biopsy via flexi-rigid pleuroscope. , $^{4,58-12,14,15}$ To the authors' best knowledge, this is the first case series of pleuroscopic cryobiopsy in the Southeast Asia region.

Pleural fluid biochemical characteristics are poor differentiators of tuberculous and malignant pleural effusions, ${ }^{16}$ as demonstrated in this case series. The higher $\mathrm{pH}$ values in Cases 2, 3, and 4 were likely due to exposure to air during collection via the suction port of the scope, causing artificial elevation of $\mathrm{pH}^{17}$ Pleural fluid cytology carries overall sensitivity of $67.2 \%$ in malignant pleural effusion of all types; of these, the sensitivity was $87.9 \%$ for adenocarcinomas but dropped to $45.5 \%$ in malignant mesothelioma. ${ }^{18}$ In this series, none of the pleural fluid cytology results were conclusive; 
only Cases 3 and 6 had abnormal fluid cytology showing malignant and atypical cells, respectively, which were later confirmed via cryobiopsy as adenocarcinoma and mesothelioma (Table 1). While the diagnostic accuracy of cytology in malignant mesothelioma has been shown to increase with the availability of an experienced cytopathologist in a region of high prevalence for mesothelioma, ${ }^{18}$ this may not be applicable in the Southeast Asia region. This highlights the unreliability of pleural fluid cytology and the need for a definitive biopsy to clinch the diagnosis. While sensitivity and specificity of flexi-rigid pleuroscopy using conventional forceps in undiagnosed exudative pleural effusion is high, ${ }^{5}$ increased false-negative results are seen in cases of thickened pleura. ${ }^{19,20}$ Some factors that contribute to this include inadequate depth of biopsy sample ${ }^{20}$ and the lack of mechanical power of the conventional forceps and a small cup size. ${ }^{4,5}$
Cryobiopsy poses a potential solution to this problem, having been shown to be non-inferior to conventional forceps in the diagnosis of malignant mesothelioma. ${ }^{21}$ The crucial advantage lies in that it can acquire significantly greater depths of tissue than conventional forceps;,4,9,10,12 one study reported extrapleural fat in $65.2 \%$ of cryobiopsy samples as opposed to $40.8 \%$ in conventional forceps biopsy. ${ }^{12}$ This was demonstrated in Case 6 (Table 1), whereby the patient's diagnosis of malignant mesothelioma was confidently obtained due to the demonstration of extrapleural fat, which is essential to visualise invasion of abnormal mesothelial cells in mesothelioma (Figure 1). In Southeast Asia, reported rates of non-specific pleuritis range from $12.0 \%^{22}$ to $21.6 \% .^{23}$
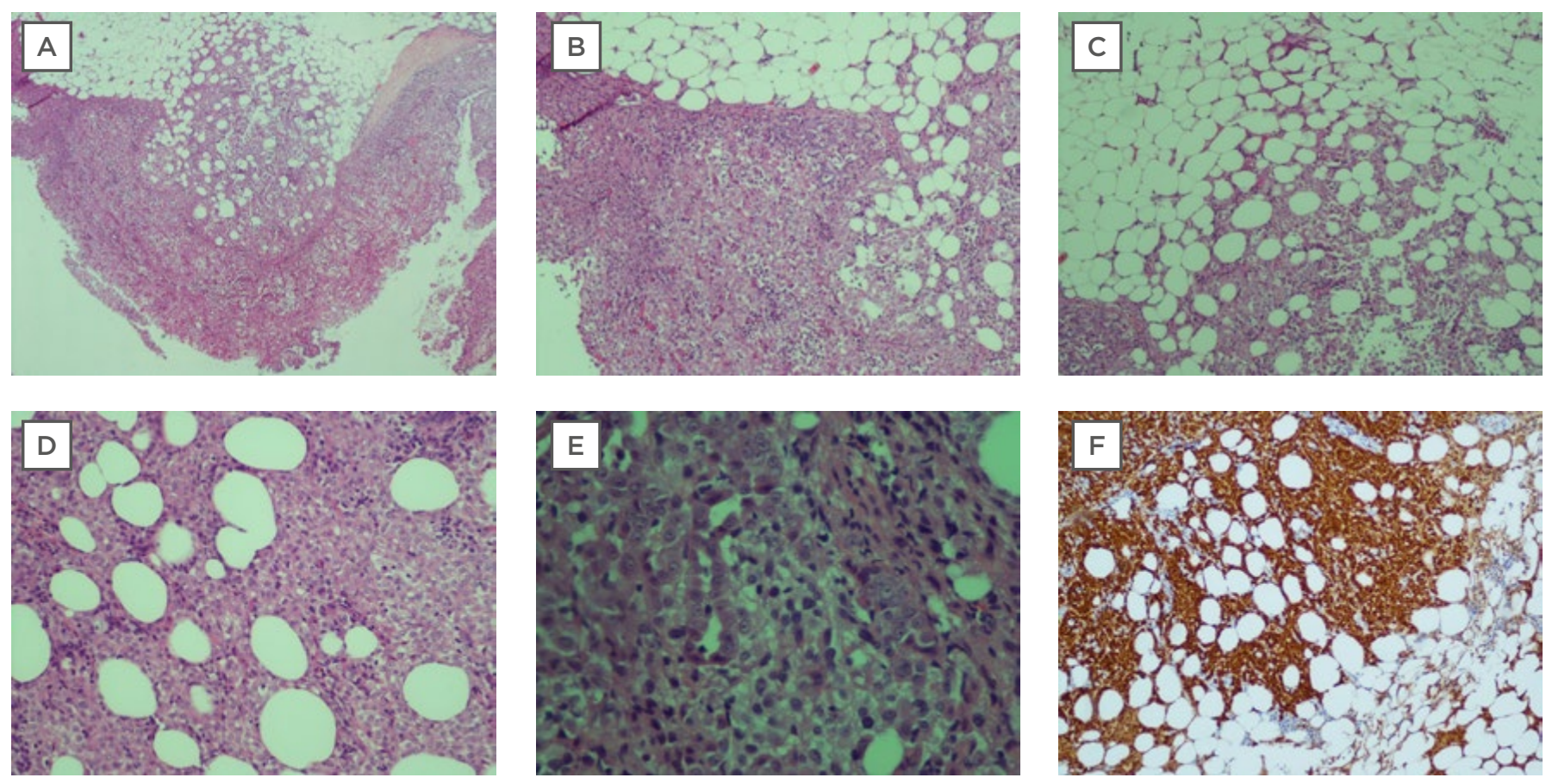

Figure 1: Cryobiopsy sample for Case 6 was conclusive for malignant mesothelioma.

A) Extrapleural adipose tissue is well demonstrated and there are no artefacts. There is marked increase of atypical mesothelial cells proliferation superficially, with infiltration into the underlying adipose tissue, which is indicative of malignancy (x40) H\&E stain. B) The tumour cells are arranged in sheets ( $x 200)$ H\&E stain. C) Tumour cells are seen infiltrating into extrapleural adipose tissue (x200) H\&E stain. D) Tumour cells infiltrating in between adipose cells (x400) H\&E stain. E) The tumour cells show round vesicular nuclei with prominent nucleoli. Tubular formation is also noted. F) Immunohistochemical staining was positive for calretinin (d: $\times 200$ )

H\&E: haemotoxylin and eosin. 
Although long-term follow-up on these cases did not frequently reveal a diagnosis of mesothelioma, ${ }^{20}$ it is prudent to consider the possibility that the low prevalence of mesothelioma in Southeast Asia may be partly contributed by shallow biopsies leading to inconclusive or alternative diagnoses. Further research could look into the value of cryobiopsy in non-specific pleuritis.

Moreover, certain varieties of mesothelioma such as desmoplastic mesothelioma make conventional biopsy extremely difficult because they are often smooth and nonnodular macroscopically. In such cases, one author has proposed a combination of incisions via electrocautery technique followed by cryobiopsy. ${ }^{21}$ Another author has suggested creating a break in the pleura with forceps prior to cryobiopsy, ${ }^{9}$ but this has to be weighed against the risk of bleeding. The present authors have yet to implement these combined methods in their pleuroscopic setting; further studies are needed to validate them.

The second advantage of the cryoprobe is its ability to biopsy samples from lesions positioned tangentially to the instrument. 4,10 As opposed to conventional forceps, which only allow forward sampling, cryoprobe can obtain tissue in a $360^{\circ}$ manner laterally. ${ }^{24}$ Similarly, in the experience with Case 4, nodules that were tangentially oriented despite having the pleuroscope at maximal angulation were much easier to sample with cryoprobe than conventional forceps. Third, in terms of technical difficulty, there is no significant difference in operator-rated difficulty when comparing cryobiopsy to conventional forceps technique, ${ }^{12}$ this is promising and may encourage more pulmonologists to adopt it in the future, although studies on its learning curve are lacking. The authors' limited experience with pleuroscopic cryobiopsy was not a major deterrent to obtaining accurate diagnosis, as evidenced by good sample sizes comparable to other larger studies, and successful histopathological diagnosis in all six of their patients (Table 2).

The most dreaded complication of cryobiopsy is always major bleeding, which was not encountered in these six cases (Table 1). Early studies have not described any significant risks of major bleeding, but various authors have advocated gentle withdrawing of the probe as essential to prevent severe haemorrhage. ${ }^{4,8-11}$ Furthermore, one author opined that in cases when the probe was already attached to the tissue but could not be gently removed, the probe should be allowed to unfreeze and resume with a shorter period of freezing. ${ }^{8}$ Freezing time of the cryoprobe should be variable, to be adjusted throughout the procedure, as to not take tissue samples deeper than the muscle layer to reduce the risk of bleeding or nerve injury. ${ }^{21}$

One of the limitations of the authors' study is that biopsy was only performed on visibly abnormal areas for at least three passes. Expert recommendations advocate at least five biopsies carried out over abnormal and normal pleura to ensure adequate tissue quality and quantity. ${ }^{25,26}$ However, these recommendations were made in regard to conventional forceps rather than cryobiopsy. In Case 6, three cryobiopsies were performed, comparable to prior studies which performed a range of one to four cryobiopsies per patient.4,8-11,14,16 The optimal number of cryobiopsies needed to balance yield and the risk of bleeding remains uncertain, this is a potential area for future research.

Another limitation of this study was that pleural biopsy for tuberculosis culture was not routinely sent. The gold standard of diagnosing pleural tuberculosis is the isolation of Mycobacterium tuberculosis in either pleural fluid or pleural tissue by culture, or demonstration of caseating granulomas in histology. ${ }^{27}$ Tuberculosis culture is important for drug sensitivity testing, but has a sensitivity of only $68.7 \%$ as opposed to $100.0 \%$ in pleuroscopy. ${ }^{28}$ Furthermore, there is often a delay in waiting for culture results. In tuberculous endemic regions at the hand of an experienced investigator, tuberculous pleurisy usually presents with characteristic inflammatory patterns on pleuroscopy, such as caseous, sagolike nodules, or fibrin deposits and loculations. ${ }^{29}$ As demonstrated in Case 4, representative appearance on pleuroscopy combined with histological finding of granuloma was sufficient to clinch the diagnosis of pleural tuberculosis. A demonstrated therapeutic response to antituberculous medication further reinforced the diagnosis of pleural tuberculous in this cohort of patients. 
In conclusion, pleuroscopic cryobiopsy was feasible with no major complications in the six subjects; samples were comparable in size to those in previous studies and had preserved tissue architecture, allowing for histopathological confirmation of diagnosis and immunohistochemistry studies. Pleuroscopic cryobiopsy may prove useful both in the diagnosis of malignant mesothelioma in regions

\section{STATEMENT OF ETHICS}

Subjects have given their written informed consent for publication of this case report and accompanying images. This article does not contain any studies with human participants or animals performed by any of the authors. The authors have no ethical conflicts to disclose.

\section{References}

1. Venekamp LN et al. Does 'idiopathic pleuritis' exist? Natural history of non-specific pleuritis diagnosed after thoracoscopy. Respiration. 2005;72(1):74-8.

2. Ali MS et al. Pleuroscopy or videoassisted thoracoscopic surgery for exudative pleural effusion: a comparative overview. J Thorac Dis. 2019;11(7):3207-16

3. Dhooria $\mathrm{S}$ et al. A randomized trial comparing the diagnostic yield of rigid and semirig-id thoracoscopy in undiagnosed pleural effusions. Respir Care. 2014;59(5):756-64.

4. Chen $\mathrm{CH}$ et al. Feasibility and safety of pleuroscopic cryobiopsy of the pleura: a pro-spective study. Can Respir J. 2018;2018:6746470.

5. Agarwal R et al. Diagnostic accuracy and safety of semirigid thoracoscopy in exudative pleural effusions: a metaanalysis. Chest. 2013;144(6):1857-67.

6. Hetzel $\mathrm{J}$ et al. Old meets modern: the use of traditional cryoprobes in the age of mo-lecular biology. Respiration. 2008;76(2):193-7.

7. Churg A et al. The separation of benign and malignant mesothelial proliferations. Am J Surg Pathol. 2000;24(9):1183-200.

8. Rozman A et al. Rigid versus semi-rigid thoracoscopy for the diagnosis of pleural dis-ease: a randomized pilot study. Respirology 2013;18(4):704-10.

9. Thomas R et al. Pleuroscopic cryoprobe biopsies of the pleura: a feasibility and safety study. Respirology. 2015;20(2):327-32.

10. Maturu VN et al. Pleuroscopic cryobiopsy: case series and systematic review. J Bron-chology Interv Pulmonol. 2015;22(3):e11-3.

11. Tousheed $\mathrm{S}$ et al. Cryobiopsy of the pleura: an improved diagnostic tool.
J Broncholo-gy Interv Pulmonol. 2018;25(1):37-41.

12. Dhooria $\mathrm{S}$ et al. Pleural cryobiopsy versus flexible forceps biopsy in subjects with undi-agnosed exudative pleural effusions undergoing semirigid thoracoscopy: a crossover randomized trial (COFFEE Trial). Respiration. 2019;98(2):133-41.

13. Bonniot JP et al. Pleural and lung cryobiopsies during thoracoscopy. Chest. 1989;95(3):492-3.

14. Pathak $\vee$ et al. Safety and feasibility of pleural cryobiopsy compared to forceps biopsy during semi-rigid pleuroscopy. Lung. 2017;195(3):371-5.

15. Wurps $\mathrm{H}$ et al. Intra-patient comparison of parietal pleural biopsies by rigid forceps, flexible forceps and cryoprobe obtained during medical thoracoscopy: a prospective series of 80 cases with pleural effusion. BMC Pulm Med. 2016;16:98.

16. Ferreiro $L$ et al. Advances in pleural effusion diagnostics. Expert Rev Respir Med. 2020;14(1):51-66.

17. Rahman NM et al. Clinically important factors influencing the diagnostic measurement of pleural fluid $\mathrm{pH}$ and glucose. Am J Respir Crit Care Med. 2008;178(5):483-90.

18. Loveland P et al. Diagnostic yield of pleural fluid cytology in malignant effusions: an Australian tertiary centre experience. Intern Med J. 2018;48(11):1318-24.

19. Davies HE et al. Outcome of patients with nonspecifific pleuritis/fibrosis on thoraco-scopic pleural biopsies. Eur J Cardiothorac Surg. 2010;38:472-7.

20. Janssen $\mathrm{J}$ et al. What is the significance of non-specific pleuritis? A trick question. Clin Respir J. 2018;12(9):2407-10
21. Nakai T et al. Cryobiopsy during flex-rigid pleuroscopy: an emerging alternative biopsy method in malignant pleural mesothelioma. A comparative study of pathology. Jpn J Clin Oncol. 2019;1;49(6):559-66.

22. Verma A et al. Effectiveness of medical thoracoscopy and thoracoscopic talc poudrage in patients with exudative pleural effusion. Singapore Med J. 2015;56(5):268-73.

23. Kho SS et al. Diagnostic yield of medical thoracoscopy in exudative pleural effusions in a region with high tuberculosis burden. Med J Malaysia 2020;75(3);254-9.

24. Kho SS et al. Performance of transbronchial cryobiopsy in eccentrically and adjacently orientated radial endobronchial ultrasound lesions. ERJ open research. 2019;5(4):00135-2019.

25. Novello $S$ et al. The Third Italian Consensus Conference for Malignant Pleural Mesothe-lioma: state of the art and recommendations. Crit Rev Oncol Hematol. 2016;104:9-20.

26. Scherpereel A et al. Guidelines of the European Respiratory Society and the European Society of Thoracic Surgeons for the management of malignant pleural mesothelio-ma. Eur Respir J. 2010;35(3):479-95

27. Shaw JA et al. Tuberculous pleural effusion. Respirology. 2019;24(10):962-71.

28. Casalini $A G$ et al. Pleural tuberculosis: medical thoracoscopy greatly increases the di-agnostic accuracy. ERJ Open Res. 2018;4(1):00046-2017.

29. Frank W, "Tuberculous pleural effusion, "Mahboub BH, Vats MG (eds.), Tuberculosis-current issues in diagnosis and management (2013), Germany: Intech, pp. 302-4. 